\title{
Effects of different trocar numbers on oxidative stress in laparoscopic cholecystectomy
}

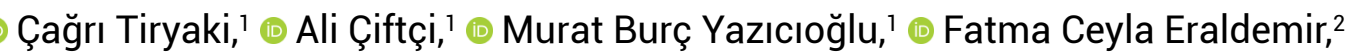

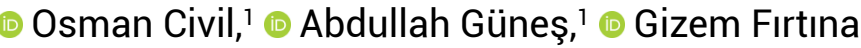 \\ 'Department of General Surgery, University of Health Science, Kocaeli Derince Training and Research Hospital, Kocaeli, Turkey \\ ${ }^{2}$ Department of Biochemistry, Kocaeli University Faculty of Medicine, Kocaeli, Turkey
}

\begin{abstract}
Introduction: Increase in intra-abdominal pressure during pneumoperitoneum (Pp), and inflation-deflation, which cause splanchnic ischemia-reperfusion (I/R), are the reasons for oxidative stress in LS. However, not only Pp and I/R but also surgical trauma has an effect on oxidative stress. This study aims to discuss the number of trocar entry effects on oxidative stress as a surgical trauma in LS.

Materials and Methods: Patients were divided into two groups; three-port cholecystectomy (group 1, n=20) and four-port cholecystectomy (group 2, n=20). All patients' venous blood samples were taken three times; preoperatively, postoperative $6^{\text {th }}$ and $24^{\text {th }}$ hours for study Malondialdehyde (MDA) and advanced oxidation protein products (AOPP) to evaluate oxidative stress.

Results: There was no statistically significant difference between the two groups. However, a statically significant difference was observed in MDA levels between preoperative and PO six hours, and duration of operation $(\mathrm{p}=0.001)$.

Conclusion: In our study, the findings showed that laparoscopic cholecystectomy (LC) can be performed safely with three or four trocars, and a similar oxidative response was observed in both groups. Surgical trauma that arises from trocar entry ( 3 or 4-trocar) did not change the oxidative stress response in our patients.
\end{abstract}

Keywords: Laparoscopic cholecystectomy; oxidative stress; surgical trauma.

\section{Introduction}

Laparoscopic cholecystectomy (LC) is considered the gold standard surgical method for the treatment of gallstone disease all over the world. Traditionally, LC is performed using four-port technique. Recent developments in laparoscopic devices and the enhancement of the surgeons' experience and capability in laparoscopy, are being forcing the technique to be modificate, such as three trocar LC, natural orifice transluminal endoscopic Surgery (NOTES) or single incision laparoscopic surgery (SILS) for improve the postoperative outcomes and cosmetic results. ${ }^{[1]}$

The term "oxidative stress" is briefly refers as an imbalance between formation of free radicals and antioxidant defense systems. ${ }^{[2]}$ It is well known that increase in intra-abdominal pressure during the pneumoperitoneum (Pp) and inflation-deflation which may cause splanch- 
nic ischemia-reperfusion (I/R) are the reason of oxidative stress. ${ }^{[3]}$ However, not only Pp and I/R, but also any kind of trauma, such as during surgerical procedures can cause oxidative stress. When laparoscopic surgery (LS) was compared with open procedure, it is obvious that lower oxidative stress will be observed in LS. This may be due to the following factors; minor surgical trauma and peritoneal cavity does not expose to room air as in open surgery ${ }^{[2]}$ However, we did not find any information about the effect of trocar number on oxidative stress in our literature review. The aim of this study was to discuss the effect of number of trocar entry on oxidative stress as a surgical trauma in LC.

\section{Materials and Methods}

This a prospective, and randomize study. The study protocol was approved by the Ethics Committee of the Kocaeli University, Faculty of Medicine, and conducted according to the Declaration of Helsinki, Good Clinical Practice Guidelines. All the patients who underwent elective cholecystectomy in our clinic and accepted provided they met our criteria, were considered for the study. All accepted patients gave their informed consent to be a participation in this study.

Forty patients who had symptomatic cholelithiasis with American Society of Anesthesiologists (ASA) score I, were divided into two groups according to used trocar numbers during cholecystectomy they underwent. The patients who have ASA score II or higher, systemic inflammatory disease, diabetes mellitus, autoimmune diseases, pregnancy, and patients otherwise incapable of providing informed consent were excluded. The patients ranged in age from 26-58 and 36-64 years, with a mean age of 47.5 and 51.1 years for group I and II respectively. All patients were operated on under general anesthesia with endotracheal intubation using standardized anesthetic technique. Nasogastric tube was used for gastric decompression, and immediately removed at the end of operation. Postoperatively, all patients received $1000 \mathrm{ml}$ of Ringer's solution and $500 \mathrm{ml}$ of 5\% isotonic glucose solution. Postoperative analgesia was achieved with two doses of tenoxicam $20 \mathrm{mg}$ in 24 hours. Venous blood samples were taken three times; preoperatively, postoptive $6^{\text {th }}$ and $24^{\text {th }}$ hours for study MDA and AOPP to evaluate oxidative stress. Plasma samples were separated from the cells by centrifugation at $1500 \mathrm{~g}$ for 10 minutes, and stored at $-80^{\circ} \mathrm{C}$ for the assay.

\section{Surgery}

All operations in group 1 and 2 were performed by the same two surgeon. There was no postoperative mortality in two groups. LC was performed with $\mathrm{CO}_{2}$ pneumoperitoneum at $14 \mathrm{mmHg}$ pressure with 3 trocar techniques, which was described in our previous study and 4 trocar techniques.

[1] Thiopental sodium $5 \mathrm{mg} / \mathrm{kg}$ is used to induce general anesthesia and Nitrous oxide is mixed in a 3:1 ratio with oxygen for maintenance. Neuromuscular blockade was achieved with pancuronium bromide $0.05 \mathrm{mg} / \mathrm{kg}$. Gastric decompression with a nasogastric tube was used in all patients, and removed at the end of operation.

\section{Statistical Analysis}

Statistical analysis of the data was performed using the Statistical Package for the Social Sciences (SPSS) version 20.0 (IBM, Chicago, IL, USA). The normal distribution conformity was assessed by using the student-t test and given as mean \pm standard deviation however Mann-Whitney $\mathrm{U}$ test was used for numerical variables which were not have normal distribution are given as median, and for categorical variables chi-square test was used and given as frequency (percentages). The difference between preop and postop period in groups were assessed by using paired samples t-test for normal distribution, on the other hand for numerical variables which were not have normal distribution Wilcoxon rank sum test was used.

\section{Results}

The characteristics of the entire study cohort are shown in Table 1 . There was no statistically significant difference in terms of age and gander between two comparing groups. However the mean operative times were 25.9 and 38.1 minutes for the group 1 and 2 respectively, and the difference was statistically significate $(\mathrm{p}=0.001)$. There were no complications such as significant hemorrhage or postoperative hemodynamic instability in two groups. The MDA,

\section{Table 1. Characteristics of the patients}

\begin{tabular}{lccc} 
& Group I & Group II & p \\
\hline $\mathrm{n}$ & 20 & 20 & \\
Age & $47.5 \pm 8.2$ & $51.1 \pm 7.7$ & $\mathrm{~ns}$ \\
Gender (female) & $16(80.0)$ & $18(90.0)$ & $\mathrm{ns}$ \\
Duration of & $25.9 \pm 8.0$ & $38.1 \pm 12.4$ & $0.001^{*}$ \\
operation (min) & & & \\
\hline Data given as mean \pm SD. NS, not significant, * ${ }^{*}<0.05$. & \\
\end{tabular}


Table 2. Preoperative and postoperative values of MDA, AOPP in both groups

\begin{tabular}{lcccc} 
Groups & Parameters & Preoperative & PO 6 $^{\text {th }}$ hour & PO 24 $^{\text {th }}$ hour $^{\text {a }}$ \\
\hline Group I (3-trocar) & MDA & $18.8 \pm 2.3^{\mathrm{a}}$ & $17.5 \pm 1.3^{\mathrm{a}}$ & $17.9(16.3-24.7)$ \\
& AOPP & $14.1(7.9-300)$ & $13.9(5.4-300)$ & $13.9(5.8-300)$ \\
Group II (4-trocar) & MDA & $17.8 \pm 2.7$ & $17.8 \pm 1.7$ & $17.2(14.5-181.3)$ \\
& AOPP & $16.1(4.1-300)$ & $16.8(8.5-300)$ & $16.4(8.4-300)$ \\
\hline
\end{tabular}

MDA: Malondialdehyde; AOPP. Advanced oxidation protein products. Data are means \pm standard deviation.

${ }^{a} \mathrm{P}=0.011$ for MDA preop vs $6^{\text {th }}$ hour levels in group $\mathrm{I}$.

and AOPP levels of groups at preoperative, postoperative (PO), $6^{\text {th }}$, and $24^{\text {th }}$ hour are given in Table 2 . There was no statistically significant difference in these parameters, however statistically significant difference was found in MDA levels at preoperative and PO $6^{\text {th }}$ hour $(\mathrm{p}=0.011)$ and duration of operation ( $\mathrm{p}=0.001$ ) between two groups.

\section{Discussion}

Nowadays, LS is widely used, and with the increasing experience in various surgical procedures, more difficult and lengthy abdominal operations have begun to be performed laparoscopically even in elderly patients. It is known that laparoscopy cause oxidative stress response. ${ }^{[4-6]}$ The term "oxidative stress" is briefly refers as an imbalance between formation of free radicals and antioxidant defense systems. ${ }^{[2]}$ In LS, oxidative stress formation was attributed to inflation-deflation related to splanchnic ischemia-reperfusion, hemodynamic changes, and $\mathrm{CO}_{2}$ pneumoperitoneum..$^{[2,7,8]}$ We know that surgical trauma produced complex physiological stress response, that activates inflammatory, endocrine, metabolic, and immunological mediators, and increased free radical formation as a result of ischemiareperfusion, leukocyte activation, and mitochondrial dysfunction. ${ }^{[3,9]}$ Free radicals are highly active molecules that have important biological functions. ${ }^{[3,7,10]}$ If the production of free radicals exceed the detoxification capacity, they may react with and damage DNA, lipids and proteins. ${ }^{[10]}$ MDA is a indicators of oxidative stress. It is a low molecular weight aldehyde that caused by the breakdown of lipid peroxyl radicals and also by oxidizing protein molecules causes more oxidative damage. ${ }^{[4,11]}$ Other indicator of oxidative stress is Carbonyl content of protein that oxidate specific amino acid residues. ${ }^{[12]} \mathrm{AOPP}$ is thought to activate mononuclear phagocytes and act like a cytokine-like mediator between neutrophils and monocytes. AOPP consists of albumin aggregates containing disulfide bridges and / or tyrosine cross-links. The AOPP-albumin structure dif- fers from pure albumin or control plasma albumin. This structure was shown using chromatographic and electrophoretic techniques. Therefore, the last cross-link product of albumin is defined as AOPP ${ }^{[13]}$ The oxidative modification products of proteins are more stable than lipids, so they become better indicators of oxidative stress, therefore AOPP is a good oxidative stress marker. ${ }^{[1]}$ So we used MDA and AOPP for oxidative stress indicator.

We was previously shown that three-port LC is a safe, convenient, and more economical technique than four-ports LC, and could be performed by experienced surgeons unless it compromises the progression of the surgery. ${ }^{[1]}$ In addition, the three-port technique caused less pain than the four-port technique, so less analgesics are required for pain control and reduce costs by reducing the hospital stay. ${ }^{[14]}$ It also leads to better cosmetic results. ${ }^{[1]}$ Therefore, in this study, we aimed to compare the oxidant effect of four and three-ports using MDA and AOPP.

Harsha et al. ${ }^{[14]}$ showed that mean operative time for threeport LC was shorter. In our study, there was a statistically significant difference between the two groups in terms of operation time ( $\mathrm{p}=0.001)$. In our previous study the mean operation time was given as $33.76 \mathrm{~min}$ (15-90 min). ${ }^{[1]}$ The same surgeon was performed the three-port operation in both of study and the mean operation time was so closed.

Surgical trauma, bowel manipulation and mesentery traction are usually less in laparoscopic procedures due to large area created by the pneumoperitoneum and enlarged appearance obtained by laparoscopy. Therefore, minor trauma and intestinal handling minimized the inflammatory response in the gut that caused less systemic inflammation, and preserved immune function results in lower oxidative stress in laparoscopic procedures. ${ }^{[15-17]}$ However, we could not find any data in the literature about oxidative stress related to trauma caused by trocar. In our study, there was a statistically significant difference between pre- 
operative and PO $6^{\text {th }}$ hour MDA levels of group I ( $\left.<<0.05\right)$. However, there was no significant deference between preop, postop 6 hour and 24 hour MDA levels of two groups ( $>0.05)$. There was a slight, insignificant decrease in MDA level at the $6^{\text {th }}$ postoperative hour compared to preoperative measurements. This is due to free radicals which were produced immediately after reperfusion and MDA plasma levels decreased on the 1st postoperative day in the LC. ${ }^{[18]}$

In conclusion, since both groups showed similar oxidative response, we can say that LC can be performed safely with three or four trocar. Surgeons often avoid complications (trocar site hernia, bleeding, etc.) that may result from an additional trocar entry during the operation. These complications can be prevented by suturing the trocar site or performing the operation with less trocar. However, since surgical trauma caused by trocar entry does not alter the oxidative stress response, the surgeon can safely use one more trocar when necessary but it should be kept in mind that patients with limited cardiac, renal and/or pulmonary functions may respond differently to $\mathrm{CO}_{2}$-induced pneumoperitoneum, so different pneumoperitoneum techniques such as different types of gas or warm and humidified environment may be an alternative for these patients. ${ }^{[19,20]}$

\section{Acknowledgements}

The authors acknowledge they have no conflicts of interest.

\section{Disclosures}

Ethichs Committee Approval: The study was approved by the Local Ethics Committee.

Peer-review: Externally peer-reviewed.

Conflict of Interest: None declared.

\section{References}

1. Ciftci A, Yazicioglu MB, Tiryaki C, Turgut HT, Subasi O, Ilgoz $M$, et al. Is the fourth port routinely required for laparoscopic cholecystectomy? Our three-port laparoscopic cholecystectomy experience. Ir J Med Sci 2016;185:909-912. [CrossRef]

2. Aktimur R, Gokakin AK, Deveci K, Atabey M, Topcu O. Oxidative stress markers in laparoscopic vs. open appendectomy for acute appendicitis: A double-blind randomized study. J Minim Access Surg 2016;12:143-7. [CrossRef]

3. Arsalani-Zadeh R, Ullah S, Khan S, MacFie J. Oxidative stress in laparoscopic versus open abdominal surgery: a systematic review. J Surg Res 2011;169:e59-68. [CrossRef]

4. Polat C, Yilmaz S, Serteser M, Koken T, Kahraman A, Dilek ON. The effect of different intraabdominal pressures on lipid peroxidation and protein oxidation status during laparoscopic cholecystectomy. Surg Endosc 2003;17:1719-22. [CrossRef]

5. Akbulut G, Polat C, Aktepe F, Yilmaz S, Kahraman A, Serteser $\mathrm{M}$, et al. The oxidative effect of prolonged $\mathrm{CO} 2$ pneumoperitoneum on renal tissue of rats. Surg Endosc 2004;18:1384-8.

6. Yilmaz S, Polat C, Kahraman A, Koken T, Arikan Y, Dilek ON, et al. The comparison of the oxidative stress effects of different gases and intra-abdominal pressures in an experimental rat model. $\mathrm{J}$ Laparoendosc Adv Surg Tech A 2004;14:165-8. [CrossRef]

7. Wong YT, Shah PC, Birkett DH, Brams DM. Carbon dioxide pneumoperitoneum causes severe peritoneal acidosis, unaltered by heating, humidification, or bicarbonate in a porcine model. Surg Endosc 2004;18:1498-503. [CrossRef]

8. Ben-Haim M, Rosenthal RJ. Causes of arterial hypertension and splachnic ischemia during acute elevations in intra-abdominal pressure with $\mathrm{CO} 2$ pneumoperitoneum: a complex central nervous system mediated response. Int J Colorectal Dis 1999;14:227-36. [CrossRef]

9. Stipancic I, Zarkovic N, Servis D, Sabolović S, Tatzber F, Busic Z. Oxidative stress markers after laparoscopic and open cholecystectomy. J Laparoendosc Adv Surg Tech A 2005;15:347-52. [CrossRef]

10. Jezek $P$, Hlavatá $L$. Mitochondria in homeostasis of reactive oxygen species in cell, tissues, and organism. Int J Biochem Cell Biol 2005;37:2478-503. [CrossRef]

11. Veyseller B, Aksoy E, Ertaş B, Keskin M, Ozturan O, Yildirim $Y S$, et al. A new oxidative stress marker in patients with nasal polyposis: advanced oxidation protein products (AOPP). BENT 2010;6:105-9.

12. Schilling $M K$, Redaelli $C$, Krähenbühl L, Signer $C$, Büchler MW. Splanchnic microcirculatory changes during CO2 laparoscopy. J Am Coll Surg 1997;184:378-82.

13. Descamps-Latscha B, Witko-Sarsat V. Importance of oxidatively modified proteins in chronic renal failure. Kidney Int Suppl 2001;78:S108-13. [CrossRef]

14. Harsha HS, Gunjiganvi M, Singh $C$, Moirangthem GS. A study of three-port versus four-port laparoscopic cholecystectomy. J Med Soc 2013;27:208-11. [CrossRef]

15. Anup R, Balasubramanian KA. Surgical stress and the gastrointestinal tract. J Surg Res 2000;92:291-300. [CrossRef]

16. Whelan RL, Franklin M, Holubar SD, Donahue J, Fowler R, Munger $\mathrm{C}$, et al. Postoperative cell mediated immune response is better preserved after laparoscopic vs open colorectal resection in humans. Surg Endosc 2003;17:972-8.

17. Schietroma M, Carlei F, Cappelli S, Amicucci G. Intestinal permeability and systemic endotoxemia after laparotomic or laparoscopic cholecystectomy. Ann Surg 2006;243:359-63.

18. Gál I, Róth E, Lantos J, Varga G, Jaberansari MT. Inflammatory mediators and surgical trauma regarding laparoscopic access: free radical mediated reactions. Acta Chir Hung 1997;36:97-9.

19. Chiu AW, Azadzoi KM, Hatzichristou DG, Siroky MB, Krane RJ, Babayan RK. Effects of intra-abdominal pressure on renal tissue perfusion during laparoscopy. J Endourol 1994;8:99-103.

20. Yavuz Y, Rønning K, Lyng 0 , Mårvik R, Grønbech JE. Effect of increased intraabdominal pressure on cardiac output and tissue blood flow assessed by color-labeled microspheres in the pig. Surg Endosc 2001;15:149-55. [CrossRef] 